\title{
Gestational diabetes mellitus is associated with increased leukocyte peroxisome proliferator-activated receptor $\gamma$ expression
}

Marzena Wójcik ${ }^{1}$, Katarzyna Mac-Marcjanek ${ }^{1}$, Iwona Nadel ${ }^{2}$, Lucyna Woźniak ${ }^{1}$, Katarzyna Cypryk ${ }^{2,3}$

1Department of Structural Biology, Medical University of Lodz, Lodz, Poland
2Polish Mother's Memorial Hospital, Research Institute, Lodz, Poland
${ }^{3}$ Diabetology and Metabolic Diseases Department, Medical University of Lodz, Lodz,
Poland

Submitted: 26 November 2013

Accepted: 6 March 2014

Arch Med Sci 2015; 11, 4: 779-787

DOI: $10.5114 /$ aoms.2015.47692

Copyright $\odot 2015$ Termedia \& Banach

\section{Abstract}

Introduction: Peroxisome proliferator-activated receptor $\gamma$ (PPAR $\gamma$ ) is a ligand-activated transcription factor of the nuclear receptor superfamily that is involved in lipid and carbohydrate metabolism as well as inflammation; thereby it participates in metabolic diseases including diabetes. Although PPAR $\gamma$ expression has been observed in different tissues of diabetic patients, its level in leukocytes from subjects affected by gestational diabetes mellitus (GDM) has not yet been reported. This study aimed to investigate leukocyte PPARG expression in GDM patients at 24-33 weeks of gestation and, in turn, to correlate these alterations with anthropometric and metabolic parameters of patients.

Material and methods: Leukocytes were isolated from the blood of normal glucose tolerant (NGT; $n=34)$ and GDM $(n=77)$ pregnant women between 24 and 33 weeks of gestation. Leukocyte PPARG mRNA expression was determined by semi-quantitative polymerase chain reaction. Univariate correlation analysis was performed to investigate associations between PPARG expression and clinical characteristics of patients.

Results: Leukocyte PPARG mRNA level was significantly higher in GDM than NGT women $(p<0.05)$. In the whole study group, PPARG expression positively correlated with plasma glucose concentrations at $1 \mathrm{~h}(r=0.222$, $p=0.049)$ and $2 \mathrm{~h}(r=0.315, p=0.020)$ of $75 \mathrm{~g}$ oral glucose tolerance test (OGTT), and negatively correlated with plasma HDL cholesterol concentration $(r=-0.351, p=0.010)$.

Conclusions: The correlation between leukocyte PPARG overexpression and hyperglycaemia suggests that PPARG mRNA expression in these cells might be up-regulated in high-glucose conditions in GDM patients at 24-33 weeks of gestation.

Key words: gestational diabetes mellitus, insulin resistance, PPAR $\gamma$, type 2 diabetes mellitus.

\section{Introduction}

Gestational diabetes mellitus (GDM), defined as glucose intolerance with onset or first recognition during pregnancy [1], is currently the most common metabolic abnormality occurring during pregnancy, affecting from $1 \%$ to $14 \%$ of all pregnancies depending on ethnic group and the diagnostic test employed [2]. The GDM is linked to numerous and serious complications for both mother and newborn. In the short term, mothers

\author{
Corresponding author: \\ Marzena Wójcik MD, PhD \\ Department \\ of Structural Biology \\ Medical University of Lodz \\ 7/9 Zeligowskiego St \\ 90-752 Lodz, Poland \\ Phone: +48 426393238 \\ E-mail: marzena.wojcik@ \\ umed.lodz.pl
}


with GDM are at an increased risk of delivering a macrosomic infant and developing preeclampsia [3], whereas their offspring are prone to neonatal hypoglycaemia, hyperbilirubinaemia, hypocalcaemia, respiratory distress syndrome, and polycythemia [4]. In the long term, GDM women are at a substantially increased risk of developing type 2 diabetes mellitus (T2DM) and cardiovascular disease after pregnancy [5, 6], and their offspring are at risk for the development of obesity and abnormal glucose metabolism during childhood, adolescence, and adulthood [7].

The GDM shares with T2DM some metabolic abnormalities, including insulin resistance and $\beta$ cell dysfunction. Although the precise mechanisms underlying the pathophysiology of GDM are not fully understood, several factors contributing to diabetic pregnancy have been identified so far. Among them, disturbances in the insulin signalling pathway [8, 9], altered plasma adipokine levels $[10,11]$ as well as inflammation [12] and oxidative stress, resulting from overproduction of free radicals and/or defects in the antioxidant defences $[13,14]$, have been found to associate with GDM.

Peroxisome proliferator-activated receptor $\gamma$ (known as PPARy or NR1C3) is a ligand-activated transcription factor with a distinct tissue distribution and different biological functions ranging from lipid and carbohydrate metabolism to immune/inflammatory responses, and control of cell proliferation/differentiation [15-17]. The PPAR interacts with a wide spectrum of natural ligands such as long-chain polyunsaturated fatty acids, prostaglandin (PG)J2 derivatives, and oxidized fatty acids, as well as of synthetic ligands such as glitazones (also known as thiazolidinediones, TZDs) $[18,19]$. From the mechanistic point of view, PPAR $\gamma$ activates transcription of their target genes as a heterodimer with the 9-cis retinoic acid-activat- ed retinoid $X$ receptors (RXRs), which bind to the PPAR response element (PPRE) sequences located within the promoters of target genes (Figure 1) [20-22]. In the absence of a ligand, the heterodimer is associated with a co-repressor that inhibits transcription through the recruitment of histone deacetylases (Figure $1 \mathrm{~A}$ ). Ligand binding to the heterodimer causes a conformational change in the protein structure of PPAR $\gamma$ resulting in dissociation of the co-repressor and recruitment of the co-activator and, in turn, transcriptional activation of target genes (Figure 1 B) $[23,24]$.

A large body of evidence indicates that PPAR $\gamma$ is linked to T2DM since it participates in the regulation of glucose and lipid metabolism, adipocyte differentiation, and inflammation. In this respect, it has been shown that PPAR $\gamma$ modulates the expression of several adipocyte-specific genes involved in lipid synthesis and storage, insulin signalling, and adipokine production $[25,26]$ and, moreover, its activation by TZDs improves insulin sensitivity in insulin-resistant animal models and diabetic patients [27]. Several dominant-negative mutations in the human PPARG gene have also been found to cause partial lipodystrophy, increased insulin resistance, diabetes, and hypertension [28]. In addition to PPAR $\gamma$ function in glucose and lipid metabolism, this transcription factor has anti-inflammatory properties and its ligands have been demonstrated to suppress production of monocyte/macrophages inflammatory cytokines such as TNF- $\alpha$, IL- 6 , and IL- $1 \beta$ through inhibiting the activity of transcription factors such as nuclear factor $\kappa$-light-chain-enhancer of activated B cells (NF- $\kappa$ B), activator protein-1 (AP-1), and signal transducers and activators of transcription (STAT) [29, 30]. Although PPAR $\gamma$ is present in immune cells, including type B and T lymphocytes as well as monocytes/ macrophages [31-33], its role in leukocytes from
A

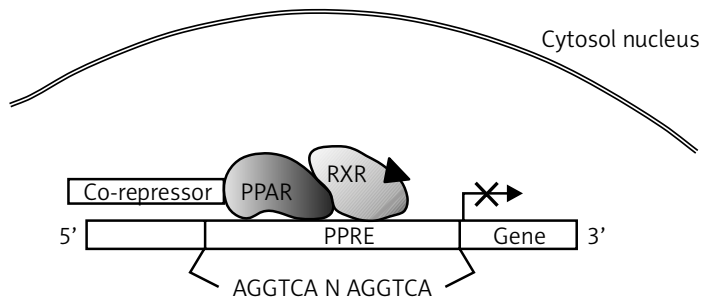

9-cis retinoic acid (RXR ligand)
B

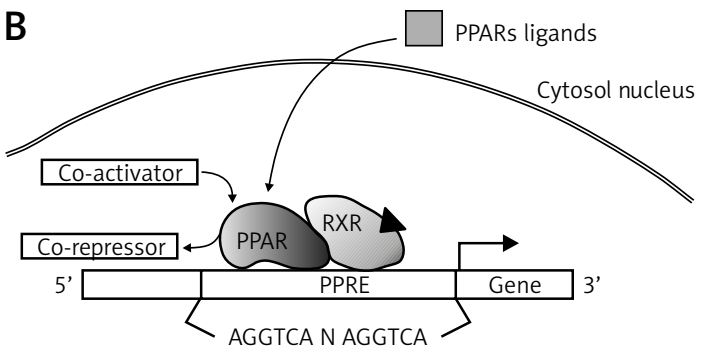

9-cis retinoic acid (RXR ligand)

Figure 1. Transcriptional activity of PPAR $\gamma$. The PPAR $\gamma$ regulates transcription of target genes as a heterodimer with the 9 -cis retinoic acid-activated retinoid $X$ receptors (RXRs), which bind to the PPAR response element (PPRE) sequences. The PPRE sequences are composed of two hexanucleotides (AGGTCA) separated by one nucleotide (this type of sequences is called DR-1) and located within the promoters of PPAR $\gamma$ target genes. A - In the absence of the PPAR $\gamma$ ligand, the heterodimer is associated with a co-repressor that inhibits transcription through the recruitment of histone deacetylases (HDACS). B - Ligand binding to the heterodimer causes a conformational change in the protein structure of PPAR $\gamma$ resulting in dissociation of the co-repressor and recruitment of the co-activator and, in turn, transcriptional activation of its target genes 
GDM women remains largely unknown. Therefore, the objective of the present study was to investigate leukocyte PPARG mRNA expression in GDM and normal glucose tolerant (NGT) pregnant women at 24-33 weeks of gestation, and, in turn, to determine correlations between alterations in PPARG expression and anthropometric and metabolic parameters of patients.

\section{Material and methods}

\section{Subject recruitment}

A total of 111 Caucasian pregnant women between 24 and 33 weeks of gestation were recruited for this study at the Polish Mother's Memorial Hospital Research Institute in Lodz, Poland. Among them, 77 subjects had GDM and 34 had NGT. The GDM was diagnosed if one or more plasma glucose levels were elevated during a $75 \mathrm{~g}$, $2 \mathrm{~h}$ oral glucose tolerance test (OGTT) according to the criteria set by WHO (modified) [34]. The inclusion criteria were the following: Caucasian ethnic background, age range between 18 and 40 years, no family history of diabetes in first-degree relatives, no GDM in a previous pregnancy, absence of any form of pre-pregnancy diabetes, absence of concomitant systemic disease (chronic or acute or infectious), not taking insulin or oral hypoglycaemic medications, no control by diet and exercise before the overnight fast.

All clinical investigations were conducted in accordance with the guidelines in the Declaration of Helsinki and were approved by the Bioethics Committee for Research on Humans at the Medical University in Lodz (No. RNN/154/09/KB from 21.04.2009). Informed consent was obtained from all participating subjects.

\section{Anthropometric and biochemical measurements}

Patients gave information on their maternal age and pre-pregnancy weight. The weight and height of patients during the third trimester of pregnancy were measured using standard methods, and both body weight gain and pre-pregnancy body mass index (BMI) expressed as weight before pregnancy divided by height squared $\left(\mathrm{kg} / \mathrm{m}^{2}\right)$ were calculated.

Blood samples were drawn after a $12 \mathrm{~h}$ overnight fast. Serum triglycerides (TGs), and HDL and LDL cholesterol levels were determined by enzymatic colorimetric methods with triglyceride GPO-PAP and the total cholesterol CHOD-PAP kits (Roche Diagnostics $\mathrm{GmbH}$, Mannheim, Germany). The glycated haemoglobin $\left(\mathrm{HbA}_{1 \mathrm{c}}\right)$ was measured by a latex enhanced turbidimetric immunoassay using specific monoclonal antibodies. Concentrations of CRP were determined by turbidimetric assay using the cassette COBAS INTEGRA C-Reactive Protein (Latex) according to the manufacturer's instructions (Roche Diagnostics GmbH, Mannheim, Germany).

The above-mentioned biochemical assays were carried out with a COBAS INTEGRA analyzer (Roche, SA). Plasma insulin was quantified using Elecsys insulin assay (Roche Diagnostics $\mathrm{GmbH}$, Mannheim, Germany). Insulin resistance and $\beta$-cell function were estimated by homeostasis model assessment (HOMA-IR and HOMA-B, respectively [35]: HOMA-IR $=$ [fasting insulin $(\mu \mathrm{U} / \mathrm{ml}) \times$ fasting glucose $(\mathrm{mg} / \mathrm{dl})] / 405$ and HOMA-B $=[360 \times$ fasting insulin $(\mu \mathrm{U} / \mathrm{ml})] /[$ fasting glucose $(\mathrm{mg} / \mathrm{dl})-63]$. To assess insulin sensitivity, the quantitative insulin sensitivity check index (QUICKI-IS) was calculated as follows: QUICKI = 1/[( $\log (10)+\log (\mathrm{G} 0)$, where I0 is the fasting plasma insulin $(\mu \mathrm{U} / \mathrm{ml})$ and $\mathrm{GO}$ is the fasting blood glucose concentration (mg/dl) [36].

\section{Leukocytes separation}

Fresh anticoagulated blood samples $(10 \mathrm{ml})$, withdrawn from each patient, were centrifuged at $3000 \mathrm{rpm}$ for $10 \mathrm{~min}$ at $4^{\circ} \mathrm{C}$. The supernatants containing plasma were discarded, and $15 \mathrm{ml}$ of red blood cell lysis buffer $\left(\mathrm{NH}_{4} \mathrm{Cl}, \mathrm{KHCO}_{3}\right.$, EDTA) was added to the leaving untouched packet cells (erythrocytes and leukocytes). After $30 \mathrm{~min}$ of erythrocyte lysis in an ice bath, aliquots were centrifuged at $4000 \mathrm{rpm}$ for $10 \mathrm{~min}$ at $4^{\circ} \mathrm{C}$, and supernatants were discarded. The pellets containing leukocytes were washed twice with phosphate-buffered saline (PBS).

\section{Gene expression assay}

Total RNA was extracted from leukocytes using a commercially available acid-phenol reagent (TriReagent, Sigma-Aldrich, USA) according to the manufacturer's procedure. RNA concentration and its purity were assessed by a LAMBDA 25 UV spectrophotometer (PerkinElmer, UK) at $U_{260}$ and $U V_{260 / 280}$, respectively. Samples were stored at $-80^{\circ} \mathrm{C}$ until use.

Reverse transcription was performed for $1 \mathrm{~h}$ at $42^{\circ} \mathrm{C}$ in a total volume of $20 \mu \mathrm{l}$ with $4 \mu \mathrm{g}$ of total RNA per sample, $1.0 \mathrm{mM}$ deoxynucleotide triphosphates (dNTPs), reverse transcriptase buffer $(5 x)$, $20 \mathrm{U}$ of RNase inhibitor, $0.5 \mu \mathrm{g}(\mathrm{dT})_{18}$ primer and $200 \mathrm{U}$ of RevertAid ${ }^{\mathrm{TM}} \mathrm{H}$ Minus M-MuLV reverse transcriptase (Fermentas, Lithuania). The resulting CDNA was subjected to polymerase chain reaction (PCR).

The PCR amplification of PPAR $\gamma$ CDNA was performed in a $20 \mu$ reaction mixture containing $1 \mathrm{U}$ of polymerase Taq, $0.2 \mathrm{mM}$ dNTPs, $1 \mu \mathrm{M}$ each primer, Taq polymerase buffer (10x), and $1 \mu$ of RT cDNA product. Amplification of PPAR $\gamma$ cDNA (471-bp fragment) was performed for 29 cycles (denaturation at $94^{\circ} \mathrm{C}$ for $30 \mathrm{~s}$, annealing at $56^{\circ} \mathrm{C}$ for $15 \mathrm{~s}$, and 
extension at $72^{\circ} \mathrm{C}$ for $30 \mathrm{~s}$ ) by using forward primer: 5' GTGCAGGAGATCACAGAGTATG 3' and reverse primer 5' GTGTTCCGTGACAATCTGTCTG 3'. Each $\mathrm{PCR}$ reaction was run in duplicate on a Thermocycler TPersonal 48 (Biometra, Germany). The amplification products were analysed on $1.2 \%$ agarose gels stained with ethidium bromide, and quantified by densitometry with the Gelix One 220 program (Biostep $\mathrm{GmbH}$, Germany). The housekeeping gene, glyceraldehyde-3-phosphate dehydrogenase $(G A P D H)$, was used to normalize reactions and for calculations of the PPARG/GAPDH ratio.

\section{Statistical analysis}

Results are shown as mean value \pm standard deviation (SD). Differences between the two groups, including clinical characteristics and expression data, were assessed by Wilcoxon's test. Relationships between leukocyte PPARG expression and each anthropometric and metabolic parameter value were determined by the nonparametric test of Spearman's rank correlation coefficient. Value of $p<0.05$ was considered as statistically significant in all analyses. Statistical analysis was performed using a statistical software package (Sta- tistica version 8.0, StatSoft, Poland, license no. AXAP911E504325AR-K).

\section{Results}

\section{Characteristics of NGT and GDM pregnant subjects}

The clinical characteristics of 77 women with GDM and 34 NGT pregnant controls, including their anthropometric and metabolic parameters, are shown in Table I. Plasma glucose concentrations at $0 \mathrm{~h}, 1 \mathrm{~h}$, and $2 \mathrm{~h}$ of $75 \mathrm{~g}$ OGTT as well as the $\mathrm{HbA}_{1 \mathrm{c}}$ levels were, as expected, significantly higher in the GDM patients compared with the NGT pregnant women $(p<0.05)$. There were no statistically significant differences between studied groups regarding plasma lipids, CRP, and insulin resistance/sensitivity $(p>0.05)$.

Leukocyte PPARG mRNA expression and its correlations with clinical characteristics of patients

We then examined leukocyte PPARG mRNA expression in the GDM versus NGT pregnant women. For this purpose, total RNA was extracted from

Table I. Clinical characteristics of all participants involved in the study

\begin{tabular}{|c|c|c|c|}
\hline Parameter & $\begin{array}{l}\text { NGT group } \\
(n=34)\end{array}$ & $\begin{array}{l}\text { GDM group } \\
(n=77)\end{array}$ & Value of $p$ \\
\hline Age [years] & $29.0 \pm 4.4$ & $29.8 \pm 4.6$ & 0.388 \\
\hline Pre-pregnancy BMI $\left[\mathrm{kg} / \mathrm{m}^{2}\right]$ & $23.7 \pm 3.9$ & $25.1 \pm 6.0$ & 0.458 \\
\hline Pregnancy BMI $\left[\mathrm{kg} / \mathrm{m}^{2}\right]$ & $27.4 \pm 3.8$ & $28.8 \pm 5.9$ & 0.230 \\
\hline Body weight gain $[\mathrm{kg}]$ & $10.7 \pm 5.6$ & $9.9 \pm 5.9$ & 0.402 \\
\hline Total cholesterol [mg/dl] & $257.9 \pm 47.7$ & $269.7 \pm 39.5$ & 0.326 \\
\hline TGs [mg/dl] & $224.0 \pm 65.8$ & $262.6 \pm 83.5$ & 0.093 \\
\hline HDL-cholesterol [mg/dl] & $78.3 \pm 13.0$ & $70.2 \pm 23.3$ & 0.147 \\
\hline LDL-cholesterol [mg/dl] & $145.4 \pm 68.3$ & $156.0 \pm 51.5$ & 0.170 \\
\hline $\mathrm{HbA}_{1 \mathrm{c}}(\%)$ & $5.2 \pm 0.4$ & $5.4 \pm 0.4$ & $0.036^{*}$ \\
\hline Glucose $0 \mathrm{~h}[\mathrm{mg} / \mathrm{dl}]$ & $77.0 \pm 6.8$ & $90.9 \pm 17.9$ & $<0.001^{*}$ \\
\hline Glucose $1 \mathrm{~h}[\mathrm{mg} / \mathrm{dl}]$ & $152.7 \pm 33.9$ & $189.4 \pm 32.7$ & $<0.001^{*}$ \\
\hline Glucose 2 h [mg/dl] & $115.6 \pm 18.8$ & $163.9 \pm 21.2$ & $<0.001^{*}$ \\
\hline Insulin $[\mu \mid \mathrm{U} / \mathrm{ml}]$ & $5.2 \pm 3.9$ & $3.5 \pm 2.9$ & 0.089 \\
\hline HOMA-IR & $1.0 \pm 0.8$ & $1.6 \pm 1.5$ & 0.211 \\
\hline HOMA-B & $120.4 \pm 94.4$ & $99.9 \pm 76.0$ & 0.573 \\
\hline QUICKI-IS & $0.4 \pm 0.1$ & $0.4 \pm 0.2$ & 0.966 \\
\hline CRP [mg/l] & $4.2 \pm 3.4$ & $3.7 \pm 2.9$ & 0.805 \\
\hline
\end{tabular}

$B M I$ - body mass index, $C R P-C$ reactive protein, $H D L$ - high-density lipoprotein, HOMA-B - homeostasis model assessment of $\beta$-cell function, HOMA-IR - homeostasis model assessment of insulin resistance, LDL - low-density lipoprotein, QUICKI-IS - quantitative insulin sensitivity check index, TG - triglycerides. Data represent the mean $\pm S D$. *Values of $p<0.05$ as compared to control as assessed by Wilcoxon's test. 
their leukocytes, and PPARG expression was measured by a semi-quantitative RT-PCR as described in Material and methods. The amplification products of PPARG (upper gel) and of the control GAPDH (lower gel) were viewed on an ethidium bromide stained electrophoresis gel as shown in Figure $2 \mathrm{~A}$. The PPARG mRNA expression, calculated as the PPARG/GAPDH ratio, showed a significant increase in the GDM group compared with the control group (0.72 \pm 0.40 vs. $0.52 \pm 0.19$, $p<0.05$ ) (Figure 2 B).

Univariate correlation analysis using the Spearman rank order correlation coefficient was performed to investigate whether leukocyte PPARG expression in the GDM women was associated with their clinical characteristics given in Table I. The PPARG mRNA expression positively correlated with plasma glucose concentrations at $1 \mathrm{~h}$ $(r=0.222, p=0.049)$ and $2 \mathrm{~h}(r=0.315, p=0.020)$ of $75 \mathrm{~g}$ OGTT in the whole study group (Table II, Figure 3). Moreover, there was a negative correlation between leukocyte PPARG mRNA expression and plasma HDL cholesterol level $(r=-0.351$, $p=0.010$ ) (Table II). No correlations were observed between leukocyte PPARG expression and other clinical parameters of patients $(p>0.05)$.

\section{Discussion}

The role of PPAR in normal placental development and trophoblast differentiation and inva-
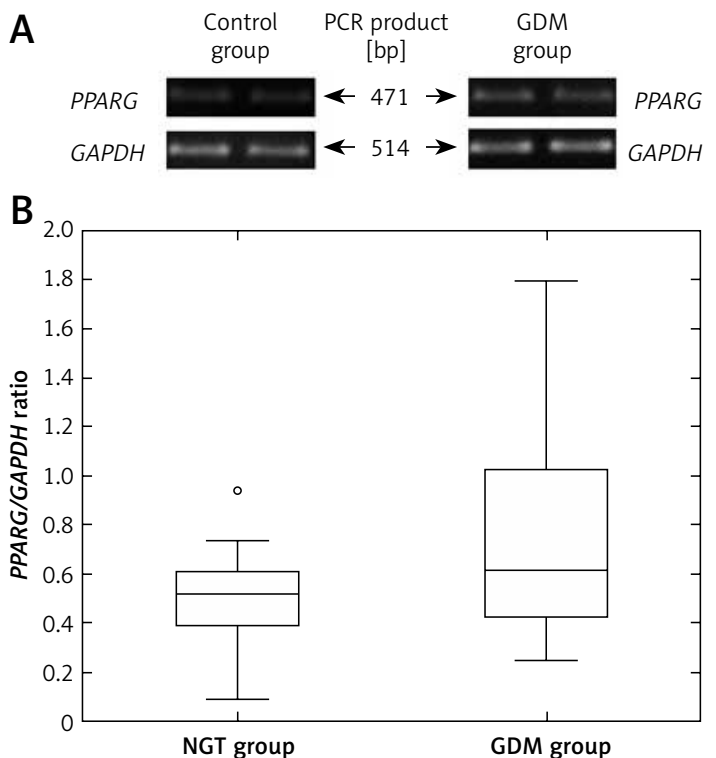

Figure 2. Leukocyte PPARG expression in the NGT and GDM pregnant subjects. A. Representative agarose gel electrophoresis for the PCR products of PPARG (upper gel) and the control GAPDH (lower gel). B. Box-plot graphs in leukocyte PPARG mRNA expression normalized to GAPDH in the NGT $(n=34)$ and $\operatorname{GDM}(n=77)$ pregnant women. Median values are presented. Differences between the groups were analysed by Wilcoxon's test. *Value of $p<0.05$ sion in gestational tissues has been established $[37,38]$. However, there is very limited knowledge about the significance of this transcription factor in human diabetic pregnancy, partially due to the poor availability of metabolic tissues from pregnant women. Therefore, to circumvent the invasive and non-ethical procedures involved in taking metabolic tissue samples from pregnant women, we used their leukocytes (including granulocytes, monocytes, and lymphocytes) as an alternative experimental cell model for investigating changes in PPARG mRNA expression. It has been reported that PPAR $\gamma$ is expressed in various cell types of the immune system, such as macrophages [31], B lymphocytes [32] and T lymphocytes [33]. Since PPAR $\gamma$ is involved in glucose and lipid metabolism in T2DM, it could be considered as an important molecular factor participating in these metabolic pathways during diabetic pregnancy. Indeed, decreased PPARG expression has been observed in subcutaneous adipose tissue from obese GDM women, suggesting that this change might be part of the molecular mechanism to accelerate fat catabolism and thereby ensure fetal nutrition in

Table II. Univariate correlations between leukocyte PPARG mRNA expression and clinical characteristics of patients in the whole study group

\begin{tabular}{|c|c|c|}
\hline \multirow[t]{2}{*}{ Parameter } & \multicolumn{2}{|c|}{ Value } \\
\hline & $r$ & $p$ \\
\hline Age [years] & -0.093 & 0.505 \\
\hline Pre-pregnancy BMI [kg/m²] & 0.183 & 0.069 \\
\hline Pregnancy BMI [kg/m²] & 0.186 & 0.183 \\
\hline Body weight gain [kg] & -0.185 & 0.064 \\
\hline Total cholesterol [mg/dl] & -0.007 & 0.961 \\
\hline TGs [mg/dl] & 0.216 & 0.116 \\
\hline HDL cholesterol [mg/dl] & -0.351 & $0.010^{*}$ \\
\hline LDL cholesterol [mg/dl] & -0.030 & 0.827 \\
\hline $\mathrm{HbA}_{1 \mathrm{c}}(\%)$ & -0.011 & 0.940 \\
\hline Glucose $0 \mathrm{~h}[\mathrm{mg} / \mathrm{dl}]$ & 0.168 & 0.108 \\
\hline Glucose $1 \mathrm{~h}[\mathrm{mg} / \mathrm{dl}]$ & 0.222 & $0.049^{*}$ \\
\hline Glucose $2 \mathrm{~h}[\mathrm{mg} / \mathrm{dl}]$ & 0.315 & $0.020^{*}$ \\
\hline Insulin $[\mu l \mathrm{U} / \mathrm{ml}]$ & -0.063 & 0.606 \\
\hline HOMA-IR & 0.115 & 0.907 \\
\hline HOMA-B & -0.061 & 0.647 \\
\hline QUICKI-IS & -0.003 & 0.977 \\
\hline CRP [mg/l] & -0.037 & 0.739 \\
\hline
\end{tabular}

$r$ - and $p$-values are given. Abbreviations are indicated in Table 1. *Significant correlation as assessed by Spearman's correlation method. 
A

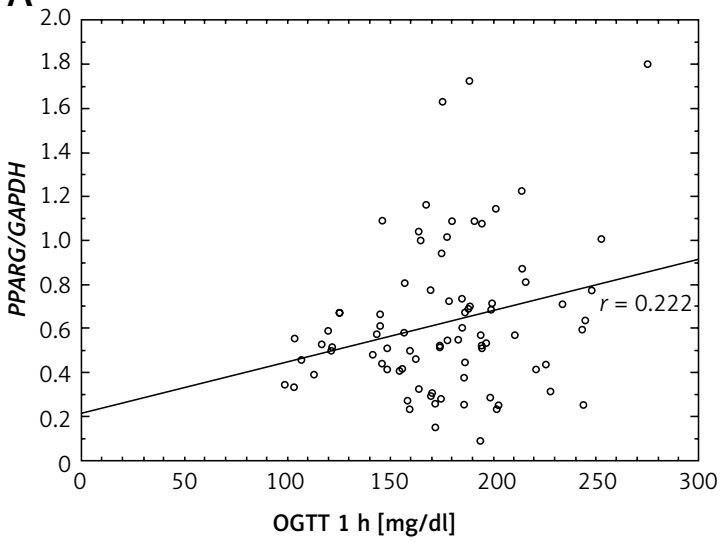

B

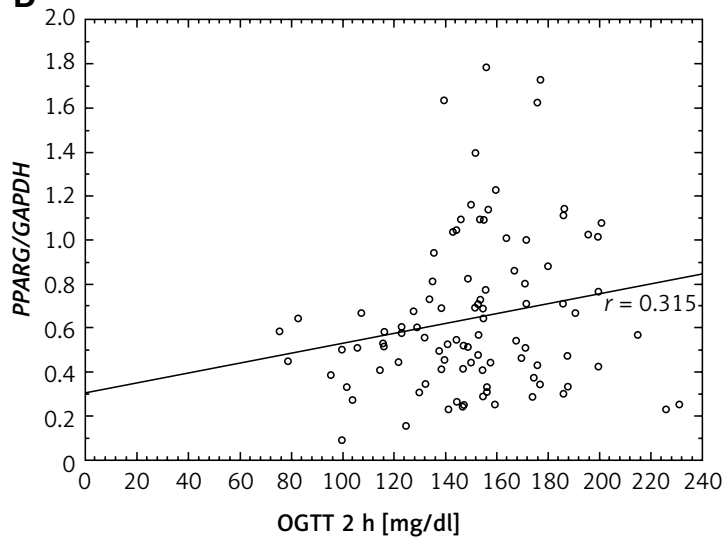

Figure 3. Positive correlations between leukocyte PPARG mRNA expression and plasma glucose concentrations at $1 \mathrm{~h}(\mathrm{~A})$ and $2 \mathrm{~h}(\mathrm{~B})$ of $75 \mathrm{~g} \mathrm{OGTT}(p<0.05)$ in the whole study group

late gestation [39]. These findings contradict our results that showed significantly higher leukocyte PPARG mRNA expression in the GDM than NGT pregnant women in late gestation. These discrepancies may partly result from tissue-specific differences in PPARG expression (adipocytes versus leukocytes) as well as differences in patient selection criteria (obese GDM women versus non-obese GDM) [39]. In the current study, no differences were observed in adiposity (i.e. pre-pregnancy and pregnancy BMI, body weight gain) between the GDM and NGT groups (Table I).

Next, we found that leukocyte PPARG mRNA expression was positively correlated with plasma glucose concentrations at $1 \mathrm{~h}$ and $2 \mathrm{~h}$ of $75 \mathrm{~g}$ OGTT in the whole study group, suggesting that hyperglycaemic conditions might up-regulate maternal leukocyte PPARG expression during the diabetic state. In accordance with this hypothesis, a significant increase in PPAR $\gamma$ expression has been demonstrated in placentas of diabetic pregnant mice with severe hyperglycaemia [40]. However, since there are also reports showing down-regulation of placenta PPAR $\gamma$ expression under mild hyperglycaemia in streptozotocin-induced diabetic rats and in gestational diabetic women [41, 42], further studies on the determination of PPAR $\gamma$ expression under different degrees of hyperglycaemic conditions in different species and cells should be performed to elucidate these discrepancies. The study by Panchapakesan et al. [43] demonstrating PPAR $\gamma$ up-regulation in the proximal tubular cell line HK-2 as a consequence of exposure to high glucose supports this line of research.

Although the reasons for elevated leukocyte PPARG expression under high-glucose conditions in the GDM patients are unclear, we cannot exclude the possibility that this change might protect against hyperglycaemia-induced oxidative stress, which appears when there is an imbalance between generation of reactive oxygen species
(ROS) and its clearance by the antioxidant defences [44]. It is now well established that under hyperglycaemic conditions in diabetes, ROS are produced during glucose autoxidation (generation of hydroxyl radicals), the polyol pathway (an increase in superoxide anion radical level), and formation of advanced glycation end products (AGEs) as a consequence of a non-enzymatic glucose reaction with proteins [45]. In recent years, several studies have observed the association between GDM and an increased level of oxidative stress $[13,14]$. Additionally, a growing body of evidence indicates that TZD PPAR $\gamma$ agonists exert anti-oxidative effects in various cells, including leukocytes [46, 47]. Taking into account these findings, it is reasonable to assume that leukocyte PPARG overexpression under hyperglycaemia in the GDM women might be a regulatory adaptation of the maternal organism to increased oxidative stress during diabetic pregnancy. However, further studies are clearly needed to investigate whether elevated leukocyte PPARG expression under high-glucose conditions could affect the expression of genes involved in oxidative stress in these cells.

The GDM affects lipid and lipoprotein metabolism; however, there are conflicting results regarding alterations in circulating lipoprotein profiles between the GDM and NGT women [48]. Among them, increased triglycerides and decreased HDL cholesterol are often detected in GDM [49]. With respect to HDL cholesterol, several studies have revealed that its low plasma level in both non-diabetic and diabetic subjects constitutes an independent risk factor for coronary heart disease [50-53]. Although current knowledge concerning the precise mechanisms underlying a reduced HDL cholesterol concentration in diabetes is far from complete, there is evidence that the impairment of reverse cholesterol transport (RCT), i.e. the process by which cholesterol is removed from peripheral cells and transported to the liver for metabolism 
and excretion in the bile, is related, at least in part, to this abnormality [54]. The PPAR $\gamma$ has been implicated in RCT as a key regulator of expression of the gene encoding the membrane-associated ATP binding cassette transporter-A1 (ABCA1) [55]. It has been shown that activation of the liver $X$ receptor- $\alpha(\operatorname{LXR} \alpha)$ by PPAR $\gamma$ upregulates $A B C A 1$ expression, resulting in an increase of apo-A1-mediated cholesterol efflux from macrophages [55, 56]. These data suggest that PPAR $\gamma$ could mediate anti-atherogenic effects by enhancing cholesterol efflux from macrophages by ABCA1. In the light of these findings, the inverse correlation between leukocyte PPARG mRNA expression and plasma HDL-cholesterol level found in the present study was rather surprising. The reasons for this association are currently unclear, but we cannot rule out the possibility out that increased PPARG expression could be linked to increased HDL removal in terms of hepatic cholesterol metabolism and biliary excretion, resulting in a low plasma HDL cholesterol. However, to explore this highly speculative hypothesis, further complex studies are required in this field. On the other hand, a positive correlation between leukocyte expression of $P P A R G$ and $A B C A 1$ in GDM subjects also remains to be proven.

In conclusion, we demonstrated for the first time that leukocyte PPARG mRNA expression was significantly elevated in the GDM women between 24 and 33 weeks of gestation and it was positively associated with hyperglycaemia, implying that PPARG expression in these cells might be up-regulated in high-glucose conditions. Surprisingly, our data also showed an inverse correlation between PPARG mRNA expression and plasma HDL cholesterol concentration. Although more studies performed on a larger population of women are required to confirm our results, these findings serve as take-off data for future research to clarify the role of leukocyte PPAR in GDM and to elucidate the cascade intracellular events linking its overexpression with hyperglycaemia as well as with low plasma HDL cholesterol level in GDM women. Furthermore, leukocytes seem to be a convenient experimental cellular model for studying GDM since there is a serious ethical problem linked to any invasive method used to obtain metabolic tissue samples from pregnant women.

\section{Acknowledgments}

These studies were supported in part by projects (no. 502-03/0-160-01/502-04-002 and 510/1107-02/510-41) from the Medical University of Lodz.

\section{Conflict of interest}

The authors declare no conflict of interest.

\section{References}

1. Buchanan TA, Xiang AH. Gestational diabetes mellitus. J Clin Invest 2005; 115: 485-91.

2. American Diabetes Association. Gestational diabetes mellitus. Diabetes Care 2003; 26: S103-5.

3. Schmidt MI, Duncan BB, Reichelt AJ, et al. Brazilian Gestational Diabetes Study Group. Gestational diabetes mellitus diagnosed with a 2 -h $75-g$ oral glucose tolerance test and adverse pregnancy outcomes. Diabetes Care 2001; 24: 1151-5.

4. Gilmartin AB, Ural SH, Repke JT. Gestational diabetes mellitus. Rev Obstet Gynecol 2008; 1: 129-34.

5. Buchanan TA. Pancreatic B-cell defects in gestational diabetes: implications for the pathogenesis and prevention of type 2 diabetes. J Clin Endocrinol Metab 2001; 86: 989-93.

6. Carr DB, Utzschneider KM, Hull RL, et al. Gestational diabetes mellitus increases the risk of cardiovascular disease in women with a family history of type 2 diabetes. Diabetes Care 2006; 29: 2078-83.

7. Metzger BE. Long-term outcomes in mothers diagnosed with gestational diabetes mellitus and their offspring. Clin Obstet Gynecol 2007; 50: 972-9.

8. Barbour LA, McCurdy CE, Hernandez TL, Kirwan JP, Catalano PM, Friedman JE. Cellular mechanisms for insulin resistance in normal pregnancy and gestational diabetes. Diabetes Care 2007; 30 (Suppl. 2): S112-9.

9. Colomiere M, Permezel M, Lappas M. Diabetes and obesity during pregnancy alter insulin signalling and glucose transporter expression in maternal skeletal muscle and subcutaneous adipose tissue. J Mol Endocrinol 2010; 44: 213-23.

10. Kautzky-Willer A, Pacini G, Tura A, et al. Increased plasma leptin in gestational diabetes. Diabetologia 2001; 44: 164-72.

11. Retnakaran R, Hanley AJ, Raif N, Connelly PW, Sermer M, Zinman B. Reduced adiponectin concentration in women with gestational diabetes: a potential factor in progression to type 2 diabetes. Diabetes Care 2004; 27: 799-800.

12. Winkler G, Cseh K, Baranyi E, et al. Tumor necrosis factor system in insulin resistance in gestational diabetes. Diabetes Res Clin Pract 2002; 56: 93-9.

13. Coughlan MT, Vervaart PP, Permezel M, Georgiou HM, Rice GE. Altered placental oxidative stress status in gestational diabetes mellitus. Placenta 2004; 25: 78-84.

14. Lappas M, Hiden U, Froehlich J, Desoye G, Haugel-de Mouzon S, Jawerbaum A.The role of oxidative stress in the pathophysiology of gestational diabetes mellitus. Antioxid Redox Signal 2011; 15: 3061-100.

15. Ison TM, Brown PJ, Sternbach DD, Henke BR. The PPARs: from orphan receptors to drug discovery. J Med Chem 2000; 43: 527-50.

16. Escher P, Wahli W. Peroxisome proliferator-activated receptors: insight into multiple cellular functions. Mutat Res 2000; 448: 121-38.

17. Yessoufou A, Wahli W. Multifaceted roles of peroxisome proliferator-activated receptors (PPARs) at the cellular and whole organism levels. Swiss Med Wkly 2010; 140: w13071.

18. Zieleniak A, Wojcik M, Wozniak LA. Structure and physiological functions of the human peroxisome proliferator-activated receptor gamma. Arch Immunol Ther Exp 2008; 56: 331-45.

19. Lehmann JM, Moore LB, Smith-Oliver TA, Wilkison WO, Willson TM, Kliewer SA. An antidiabetic thiazolidinedione is a high affinity ligand for peroxisome prolifera- 
tor-activated receptor gamma (PPAR-gamma). J Biol Chem 1995; 270: 12953-6.

20. IJpenberg A, Jeannin E, Wahli W, Desvergne B. Polarity and specific sequence requirements of peroxisome proliferator-activated receptor (PPAR)/retinoid X receptor heterodimer binding to DNA. J Biol Chem 1997; 272: 20108-17.

21. Kliewer SA, Umesono K, Mangelsdorf DJ, Evans RM. Retinoid $\mathrm{X}$ receptor interacts with nuclear receptors in retinoic acid, thyroid hormone and vitamin D3 signalling. Nature 1992; 355: 446-9.

22. Kliewer SA, Umesono K, Noonan DJ, Heyman RA, Evans RM. Convergence of 9-cis retinoic acid and peroxisome proliferator signalling pathways through heterodimer formation of their receptors. Nature 1992; 358: 771-4.

23. Zoete V, Grosdidier A, Michielin O. Peroxisome proliferator-activated receptor structures: ligand specificity, molecular switch and interactions with regulators. Biochim Biophys Acta 2007; 1771: 915-25.

24. Yu S, Reddy JK. Transcription coactivators for peroxisome proliferator activated receptors. Biochim Biophys Acta 2007; 1771: 936-51.

25. He W, Barak Y, Hevener A, et al. Adipose-specific peroxisome proliferator-activated receptor gamma knockout causes insulin resistance in fat and liver but not in muscle. Proc Natl Acad Sci USA 2003; 100: 15712-7.

26. Lehrke M, Lazar MA. The many faces of PPARgamma. Cell 2005; 123: 993-9.

27. Olefsky JM. Treatment of insulin resistance with peroxisome proliferator-activated receptor gamma agonists. J Clin Invest 2000; 106: 467-72.

28. Barroso I, Gurnell M, Crowley VE, et al. Dominant negative mutations in human PPARgamma associated with severe insulin resistance, diabetes mellitus and hypertension. Nature 1999; 402: 880-3.

29. Ricote M, Li AC, Willson TM, Kelly CJ, Glass CK. The peroxisome proliferator-activated receptor-gamma is a negative regulator of macrophage activation. Nature 1998; 391: 79-82.

30. Jiang C, Ting AT, Seed B. PPAR-gamma agonists inhibit production of monocyte inflammatory cytokines. Nature 1998; 391: 82-6.

31. Marx N, Sukhova G, Murphy C, Libby P, Plutzky J. Macrophages in human atheroma contain PPARgamma: differentiation-dependent peroxisomal proliferator-activated receptor gamma (PPARgamma) expression and reduction of MMP-9 activity through PPARgamma activation in mononuclear phagocytes in vitro. Am J Pathol 1998; 153: 17-23.

32. Schlezinger JJ, Jensen BA, Mann KK, Ryu HY, Sherr DH. Peroxisome proliferator-activated receptor gamma-mediated NF-kappaB activation and apoptosis in pre-B cells. J Immunol 2002; 169: 6831-41.

33. Clark RB, Bishop-Bailey D, Estrada-Hernandez T, Hla T, Puddington L, Padula SJ. The nuclear receptor PPAR-gamma and immunoregulation: PPAR-gamma mediates inhibition of helper T cell responses. J Immunol 2000; 164: 1364-71.

34. Definition and diagnosis of diabetes mellitus and intermediate hyperglycemia: Report of WHO/IDF consultation. World Health Organization and International Diabetes Federation. WHO Document Production Services Geneva Switzerland 2006.

35. Matthews DR, Hosker JP, Rudenski AS, Naylor BA, Treacher DF, Turner RC. Homeostasis model assessment: insulin resistance and beta-cell function from fasting plasma glucose and insulin concentrations in man. Diabetologia 1985; 28: 412-9.

36. Katz A, Nambi SS, Mather K, et al. Quantitative insulin sensitivity check index: a simple, accurate method for assessing insulin sensitivity in humans. J Clin Endocrinol Metab 2000; 85: 2402-10.

37. Barak Y, Nelson MC, Ong ES, et al. PPAR gamma is required for placental, cardiac and adipose tissue development. Mol Cell 1999; 4: 585-95.

38. Tarrade A, Schoonjans K, Pavan L, et al. PPARgamma/ RXRalpha heterodimers control human trophoblast invasion. J Clin Endocrinol Metab 2001; 86: 5017-24.

39. Catalano PM, Nizielski SE, Shao J, Preston L, Qiao L, Friedman JE. Downregulated IRS-1 and PPARgamma in obese women with gestational diabetes: relationship to FFA during pregnancy. Am J Physiol Endocrinol Metab 2002; 282: E522-33.

40. Suwaki N, Masuyama H, Masumoto A, Takamoto N, Hiramatsu $Y$. Expression and potential role of peroxisome proliferator-activated receptor gamma in the placenta of diabetic pregnancy. Placenta 2007; 28: 315-23.

41. Capobianco E, Jawerbaum A, Romanini MC, et al. 15-Deoxy-Delta12,14-prostaglandin 12 and peroxisome proliferator-activated receptor gamma (PPARgamma) levels in term placental tissues from control and diabetic rats: modulatory effects of a PPARgamma agonist on nitridergic and lipid placental metabolism. Reprod Fertil Dev 2005; 17: 423-33.

42. Jawerbaum A, Capobianco E, Pustovrh C, et al. Influence of peroxisome proliferator-activated receptor gamma activation by its endogenous ligand 15-deoxy Delta12,14 prostaglandin $\mathrm{J} 2$ on nitric oxide production in term placental tissues from diabetic women. Mol Hum Reprod 2004; 10: 671-6.

43. Panchapakesan U, Pollock CA, Chen XM. The effect of high glucose and PPAR-gamma agonists on PPAR-gamma expression and function in HK-2 cells. Am J Physiol Renal Physiol 2004; 287: F528-34

44. Wojcik M, Burzynska-Pedziwiatr I, Wozniak LA. A review of natural and synthetic antioxidants important for health and longevity. Curr Med Chem 2010; 17: 326288.

45. Wozniak LA, Cypryk K, Wojcik M. Molecular mechanisms of diabetes prevention by structurally diverse antioxidants. Nutritional and therapeutic interventions for diabetes and metabolic syndrome. Elsevier Inc.: Academic Press 2012.

46. Mattos RT, Bosco AA, Nogueira-Machado JA. Rosiglitazone, a PPAR-gamma agonist, inhibits VEGF secretion by peripheral blood mononuclear cells and ROS production by human leukocytes. Inflamm Res 2012; 61: 37-41.

47. Garg R, Kumbkarni Y, Aljada A, et al. Troglitazone reduces reactive oxygen species generation by leukocytes and lipid peroxidation and improves flow-mediated vasodilatation in obese subjects. Hypertension 2000; 36 : 430-5.

48. Herrera E, Ortega-Senovilla H. Disturbances in lipid metabolism in diabetic pregnancy. Are these the cause of the problem? Best Pract Res Clin Endocrinol Metab 2010; 24: 515-25.

49. Knopp RH, Chapman M, Bergelin R, Wahl PW, Warth MR, Irvine S. Relationships of lipoprotein lipids to mild fasting hyperglycemia and diabetes in pregnancy. Diabetes Care 1980; 3: 416-20.

50. Maron DJ. The epidemiology of low levels of high-density lipoprotein cholesterol in patients with and without coronary artery disease. Am J Cardiol 2000; 86: L11-4. 
51. Sharrett AR, Ballantyne CM, Coady SA, et al. Coronary heart disease prediction from lipoprotein cholesterol levels, triglycerides, lipoprotein (a), apolipoproteins A-I and B, and HDL density subfractions: the Atherosclerosis Risk in Communities (ARIC) Study. Circulation 2001; 104: 1108-13.

52. Gotto AM Jr, Brinton EA. Assessing low levels of high-density lipoprotein cholesterol as a risk factor in coronary heart disease: a working group report and update. J Am Coll Cardiol 2004; 43: 717-24.

53. Boden WE. High-density lipoprotein cholesterol as an independent risk factor in cardiovascular disease: assessing the data from Framingham to the Veterans Affairs High-Density Lipoprotein Intervention Trial. Am J Cardiol 2000; 86: L19-22.

54. Krentz A. Lipoprotein abnormalities and their consequences for patients with type 2 diabetes. Diabetes Obes Metab 2003; 5 (Suppl. 1): S19-27.

55. Chawla A, Boisvert WA, Lee CH, et al. A PPARgammaLXR-ABCA1 pathway in macrophages is involved in cholesterol efflux and atherogenesis. Mol Cell 2001; 7 : 161-71.

56. Chinetti G, Lestavel S, Bocher V, et al. PPAR-alpha and PPAR-gamma activators induce cholesterol removal from human macrophage foam cells through stimulation of the ABCA1 pathway. Nat Med 2001; 7: 53-8. 